\title{
ICT and Free Open Source Software in Developing Countries
}

\author{
Pia Krakowski \\ School of Economics and Commercial Law, University of Gothenburg, \\ Sweden, pia.krakowski@gmail.com
}

\begin{abstract}
The topic of this essay is if and how the use of information and communications technologies, (ICT), as well as the use of free open source software, can change the prerequisites of third world countries. Many people consider that the Internet is not only access to unlimited information, but also has a potential to make a difference in the development of human rights and democracy. Information and communications technologies, free software, and open source have a big role to play in this context. The importance of access is an issue: one tends to focus mainly on the physical access, which is only a small part in this connection. There are other types of limitations to access: the technology should be appropriate, be affordable, and a political will to provide all citizens with equal possibilities should support the introduction of the technologies. Who has access to these new technologies? Who does not have such access? Finally, we discuss a field study of an open source project in Namibia and their conclusions.
\end{abstract}

Keywords: access, digital divide, ICT, free open source software, developing countries

This essay assumes certain basic knowledge in the subject of free software, open source, and Information and Communication Technology. It is not the purpose to explain these concepts, ideas, and theories in this essay; we assume that the reader knows the background to different philosophies within the subject before reading the text below.

Common abbreviations that are used are:

FLOSS Free/Libre and Open Source Software

FOSS Free Open Source Software

FSF Free Software Foundation

ICT Information and Communication Technology

IT Information Technology

Please use the following format when citing this chapter:

Krakowski, P., 2006, in IFIP Intemational Federation for Information Processing, Volume 223, Social Informatics: An Information Society for All? In Remembrance of Rob Kling, eds. Berleur, J., Numinen, M. I, Impagliazzo, J., (Boston: Springer), pp. $319-330$. 


\section{OSS Open Source Software \\ SNN SchoolNet Namibia \\ TCO Total Cost of Ownership}

\section{Introduction}

The world is unfair. Some countries have stable economies and are at the forefront of the technical development; others are deeply in debt and have populations suffering from famine, disease, and poor economical and educational conditions. The gap between the industrialized world and the developing countries is still very large and if one studies in particular the information technological prerequisites the differences are enormous. What one in Sweden take for granted, there is at other places a lack of awareness about; at the same time as we discuss the speed of the broadband, large parts of the world still don't have a phone line connected into the village.

According to Statistiska Centralbyrån (Statistical Central Bureau), SCB, 82\% of Sweden's population between the ages 16 and 74 had used the Internet in 2004 . Disregarding the oldest people in the investigation, 55-74 years of age, the national average is about $90 \%$ [SCB, 2005-10-17]. This is a huge number if you compare it to rest of the world. According to the $\mathrm{UN}$ report E-commerce and development report 2004 [UNCTAD, 2005-10-17] 12\% (about 676 million people) of the world's population had Internet access by the end of 2003, which was an increase by 50 million people in comparison with the year before (2002). The largest part of this increase, $75 \%$, took place in the developing world. Even if the number of Internet users is increasing in the developing countries, a few countries stand for the largest increase. China, Korea, India, Brazil, and Mexico inhabit $62 \%$ of all Internet users in third world countries [UNCTAD, 2005-10-17]. Africa has 12 million Internet users compared to North America's 175 million [UNCTAD, 2005-10-17] or Europe's 188 million users [UNCTAD, 2005-10-17]. Africa has slightly more Internet users then all the population of Oceana counted together (Australia, New Zeeland et cetera), about 12 million inhabitants [UNCTAD, 2005-10-17].

Can the introduction of free and open source software and the use of ICT in any way change the prerequisites of the developing countries? In what ways can free software, open source, and ICT change the development of a country? Is it the software that is the main need in focus for the developing world, or is it something else? Are the opinions about free and open software and ICT the same in the industrialized and the developing world?

This essay intends to give an overview of the different problems and possibilities with ICT and free and open software, and highlights the research and discussions under debate now. Further, we present a comparison between the political views of the subject in Europe and Africa. In addition, we provide a short summary and discussion about a Swedish study made in Namibia, performed by two students from the Department of Informatics at the University of Gothenburg. 


\section{Theory}

The theory model of this essay is inductive, which in this context means that the author tried to derive general principles from known facts. Theories about ICT and the use of FOSS connect to a real life example in the description of the Namibia case study. This being a short essay, we should accept the reliability of the results with some reservations.

In what ways can ICTs matter in the context of developing countries? Many people consider, and the UN with them, that ICT can play an enormously big role for the development of the non-industrialized world. In the report E-commerce and development report 2004, the UN writes, "Information and communications technologies have considerable potential to promote development and economic growth. (...) In the hands of developing countries, (...) the use of ICTs can bring impressive gains in employment, gender equality and standards of living." [UNCTAD, 2005-10-17].

In this essay, the author will try to support the theory that the use of ICT and free open source software can change the prerequisites of developing countries. One of the arguments for this claim is the noted success of the Swedish government's commitment to enable Internet access for all its citizens. This is a good example of the need for a strong political will to enable the evolvement for any country to enter the IT era; it is also a good example of how one can decrease the digital divide within a country. Can you apply the example above from a western industrialized nation to the situation of the developing world? It is certainly not applicable to $100 \%$, but this is where the importance of FOSS comes in. Free and open source software enables a cheaper way to introduce information and communication technologies to citizens of the developing world and by doing so, reducing the digital divide between and within these countries.

\section{Discussion}

\subsection{General}

The discussion of the importance of ICT and free software and its possibility to affect the conditions for many of the world's underdeveloped countries is a constant topic in many forums. Where large companies see disadvantages and feel the competition from the free software advocates, others mean that ICT and free software opens up for the possibilities for countries to give their inhabitants access to computers, applications and above all, the Internet. The Internet is not only the access to unlimited information, but also has a potential to make a difference in the development of human rights and democracy. Some mean that ICT, free software, and open source have a big role to play in this context. The website $<$ www.bridges.org $>$ is an organization that strives to give more people the possibility and access to ICT in developing countries. They are working with reducing what people call the digital divide between countries. With the concept of the digital divide, one can shortly say that it means the difference between the ones that have 
access to ICT and the ones that do not. On the Bridges website, one can read reports about different projects illustrating the use of open source software in different contexts to prepare developing countries for the possibilities of ICT. Bridges shows that free and open source software during the last couple of years have become a relevant alternative to non-free software ${ }^{1}$ for countries that cannot afford to pay expensive licenses fees.

Bridges has recently published the report Free/open source software (FOSS) policy in Africa: A toolkit for policy-makers and practitioners at their website [bridges.org1, 2005-10-16]. The report is a support for governments that "... are investigating whether and how they can integrate FOSS into their strategies for social and economic development". The report discusses the African nations' attitudes against FOSS and it indicates that so far no African country has formulated a strategy that is in strong favor of FOSS as, for example, Brazil, Peru, and Malaysia have done. However, we note that several countries have at least started the work. The country that has reached the furthest with ICT in Africa is South Africa. The South Africa government has issued a policy regarding open source software (OSS), where it says that: "Government will implement OSS where analysis shows it to be the appropriate option. The primary criteria for selecting software solutions will remain the improvement of efficiency, effectiveness, and economy of service delivery by Government to its citizens. OSS offers significant indirect advantages. Where the direct advantages and disadvantages of OSS and PS (Proprietary Software) are equally strong and where circumstances in the specific situation do not render it inappropriate, opting for OSS will be preferable [bridges.org1, 2005-10-16]. Namibia, where a field study will be discussed later on in the essay, has a relatively large amount of FOSS related activities and users, where among others the organization SchoolNet Namibia (SNN) are leading a big campaign to install computers and free open source software's on schools all over the country.

\subsection{Europe: Pragmatic and Social Reasons}

Regarding Europe Rishab Aiyer Gosh recently published a report about the European Unions' attitude against FOSS, The European Politics of F/OSS Adoption. The report formed a port of a larger collection of reports published by the Social Science Research Council (SSRC), a New York based, independent organization of researchers and experts effective within different subject areas, such for example how ICT can be used to change the society and the conditions for its citizens [Gosh, 2005-10-18]. The report discusses several practical example of different FOSS projects and strategies, as for example the German city of Munich's' commitment to Linux, called LiMux. Rishab Aiyer Gosh means that there are two big reasons for the positive attitude within EU against FOSS, one more pragmatical with lower costs, better security and independence from individual suppliers, and a more social perspective where it is regarded that free software gives more freedom and local control and strengthens then democracy [Gosh, 2005-10-18]. Especially for government organizations, the possibility to change and configure the software without surveillance from the supplier is of major significance; one does not want to be dependent on certain large American companies. Gosh quotes Microsoft's Jim 
Allchin that with his clearly nationalistic approach can make any government wonder what they install in their networks: "I'm an American, I believe in the American Way. I worry if the government encourages free software, and I don't think we've done enough education of policy makers to understand the threat" [Gosh, 2005-10-18]. Another factor Gosh emphasizes is the constraint to use some companies' software to be compliant with other organizations, to upgrade when other organizations upgrade, and forced to use the same companies' byproducts, because otherwise, the formats do not support each other. One has, to put it briefly, no freedom of choice. Because patent protected software, proprietary software, does not allow a manipulation of the source code, nor make the code public, the free software advocates cannot control how the proprietary code acts or process the data the proprietary software produces. Thus one cannot fully be compatible with the patent protected applications neither compete with the software's that can, i.e. software's that are owned by the same companies. The suppliers then create a company based de facto standard and ensure their position on the market [Gosh, 2005-10-18].

\subsection{Third world: piracy, cost- and security reasons}

The Finland based researcher Niranjan Rajani has studied the importance of Free/Libre and Open Source Software (FLOSS) for developing countries [Rajani, 2005-10-17]. In his report, Free as in Education: Significance of the Free/Libre and Open Source Software for Developing Countries, Rajani discusses the right to education in comparison to the right to free software. Where the Free Software Foundation (FSF) says: "'Free software' is a matter of liberty, not price.

To understand the concept, you should think of 'free' as in 'free speech', not as in 'free beer'. [FSF, 2005-10-17] Rajani makes an addition statement and indicates that the price, despite what FSF says, is relevant in the case of developing countries. Rajani states, "From the point of view of the developing countries, we would argue that though the freedom is of paramount importance in more than one way, the price aspect is also very important, without which developing nations would not be able to significantly meet the challenges of the computer age. In fact, the Freedom aspect can be seen in terms of 'free education', which ought to be free in terms of freedom as well as price." [Rajani, 2005-10-17]. The reasoning of Rajani is not a matter of course. In Sweden, education is free and relatively open and objective, a condition that is not obvious in many other parts of the world. Rajani takes Saudi Arabia as an example, where he means that even though the education is free, free meaning gratis, it is not open and objective - free and independent - but strictly regulated.

We can relate the analysis of Rishab Aiyer Goshs in The European Politics of F/OSS Adoption about the reasons for Europe having a positive attitude to FOSS to Rajani's discussion about the developing countries premier arguments to use FLOSS $^{2}$. The logic of both the researchers follows the same line. Rajani notes the following three important reasons in Free as in Education: Significance of the Free/Libre and Open Source Software for Developing Countries for why developing countries should consider using free software [Rajani, 2005-10-17]:

1. Lower Cost

2. The Anti-Piracy Campaign 
3. Security and Technological Independence

First, the cost to migrate today's non-free systems to free software does not exceed the cost for the patent protected software licenses. Secondly, in many developing countries people can use illegal copies and do not have to pay any license fees. The severe pressure from the U.S, where the largest software companies are based, forces many countries to realize that this cannot go on any longer. Free and open software can be an alternative for developing countries that cannot afford to pay expensive license fees. Third, many countries consider frightening the U.S. world domination on the software market. By taking control over the software, one prevents unwelcome installation of spy programs on one's software.

Further, Rajani describes one more factor: the aspect of language. Much non-free software is released in a limited number of language variations as English, Spanish or for that matter, Swedish. African languages are not top priority. Here, free software can contribute with a number different products and adaptations to local languages. Ubuntu is an African adjusted Linux distribution that tries to set things right regarding the language problem. On Ubuntu's website they say among other things that: "software tools should be usable by people in their local language" [Ubuntu1, 2006-04-22]. The Ubuntu Linux distribution is an excellent alternative, if you compare it with Rajani's three reasons one should consider migrating to free software: the operating system is free ("Ubuntu will always be free of charge"). In addition, it supplies the source code for modification ("You have the right to modify your software until it works the way you want it to"), [Ubuntu2, 2006-04-22]. ${ }^{3}$

\subsection{What does real access mean?}

The organization <www.bridges.org $>$ focuses a lot on the concept of real access [bridges.org2, 2005-10-16]. They mean that real access is much more than just the physical access: "Providing access to technology is critical, but it must be about more than just physical access. Computers and connections are insufficient if the technology is not used effectively because it is not affordable; if people do not understand how to put it to use or if they are discouraged from using it; or if the local economy cannot sustain its use." Just because some free software is gratis, it does not mean that it solves the problem with the digital divide; the digital divide includes so much more. According to Bridges, Africa has for example "only $0.25 \%$ of all Internet hosts in the world, and that percentage is decreasing" [bridges.org2, 200510-16]. In some third world countries, one lacks the basic, fundamental ICT infrastructure. Except for the physical ICT infrastructure, Bridges shows that the installation and use of correct and appropriate technology is also very important to consider. They have set up twelve criteria for what real access means and by comparing the reality of the citizens against these criteria, one can decide whether people have or have not real access to ICT; that is, "access that goes beyond just physical access and makes it possible for people to use technology effectively to improve their lives."

We can summarize these criteria with the following key words:

- Physical access

- Appropriate technology 
- Affordability

- Capacity

- Relevant content

- Integration

- Socio-cultural factors

- Trust

- Legal and regulatory framework

- Local economic environment

- Macro-economic environment

- Political will

Bridges simply implies that we should adjust technology to human beings and their needs, not the other way around. However, at the same time, one should inform people about the advantages and the future prospects of information and communication technologies. At government level, one must conduct a political debate that promotes ICT and FOSS and that tries to give all citizens of a society the possibility to take part of the global information society. The purpose of the Internet is not only for the well educated classes that work in offices in the big cities, but also for less fortunate citizens in a society. With the idea of affordability, Bridges want to illustrate the significance of the economical factor. The average American Internet user spends about $1.2 \%$ of their average income on their Internet access. In comparison with countries of smaller means like for example Madagascar $(614 \%$ of the average income), Nepal (278\% of the average income), Bangladesh (191\% of the average income), or Sri Lanka (60\% of the average income) the differences, and for that matter the possibilities, are enormous [bridges.org2, 2005-10-16]. If considering Sweden as a positive example, one can note that the municipalities committed themselves very early to provide the community with Internet-connected libraries, where all citizens could have access to computers and surf the Internet gratis. This is just the needed strategy, according to Bridges, a political will to provide all citizens with equal possibilities.

\subsection{Local Development}

The absence of ICT infrastructure implies other limitations beside that you are deprived from the possibility to take part to the global information society. The development of local open and free software cannot take place without basic fundamental ICT infrastructure. Sometimes one can hear critical voices regarding why so little open source software development takes part in developing countries. Nevertheless, the arguments are a bit contradicting. A large part of the culture surrounding open source and the development of free software depend on common, repeatedly developing activities where people from all over the world contribute with the help of Internet. Eric Raymond in his famous (in open source circles) article The Cathedral and the Bazaar writes "cheap Internet was a necessary condition for the Linux model to evolve..." [Raymond, 2006-04-22]. As shown, the possibility to constant Internet access is not a matter worldwide. 


\subsection{A simple investigation}

The website <http://sourceforge.net/> is the world's largest website for developers working with open source and free software. They have over 100,000 projects and over one million registered users. Here one can host one's open source project and take part in the development of thousands of others. Here you can of course also download other open source applications.

Making a simple investigation of which types of projects are operating at Sourceforge right now [Sourceforge, 2005-10-18], by searching on the website on a number of selected key words such as Africa, Europe, and America, one can easily reveal what types of open source projects that occur at different places in the world.

Using the key word Africa gives you a number of now ongoing projects, of which quite a few school projects, plus a couple of games. For instance, you get these two below descriptions of projects within the educational area:

Edu-SLUG "Edu-SLUG is the educational software part of SLUG, the Schools Linux User Group in South Africa. SLUG installs low-cost Linux networks at schools. Edu-SLUG aims to produce software to aid teachers in education using the Outcomes Based Education system."

OpenSchool The aim of this project is to create local educational content for Southern Africa, applying Open Source principles and engaging South Africans from disadvantaged backgrounds in the Information Society, thus contributing to an improved understanding of $O p$.

On the key word Europe, you get quite a few games, game consoles, stock software, development tools, and software to search for cheap airline tickets.

On the key word America, you get several games, development tools, and a web portal for students to exchange books.

None of the two last key words (Europe, America) resulted in a project that was about education, or that gave people access to education or information. Admittedly, you obtained a website for exchanging books among students though it could have been a website for exchanging any books what so ever. It did not have anything to do with the education system. This investigation is of course not very scientific and has very limited reliability. Nevertheless, it still says something about the type of open source projects carried out in the world. It says something about the different types of needs people have in different places.

\section{Example}

\subsection{Introduction of case study}

Two students, Carolina Hafström and Jessica Hofbauer of the Department of Informatics (at the School of Economic and Commercial Law, University of Gothenburg, Sweden), did their master theses as a field study in Namibia [Hafström, Hofbauer, 2005-10-16]. Their focus was to study which factors were critical for a successful IT-adaptation in a developing country. They stayed a month in Namibia and they did their field study at SchoolNet. The students observed and interviewed 
the people involved in the project. SchoolNet is an organization that works to provide all Namibian schools with computers and Internet access by the use of donated computers and open source software [SchoolNet, 2005-10-16]. The goal of Hafström and Hofbauer's study was to investigate whether or not the users accepted well the open source technology.

\subsection{Discussion and result of case study}

Hafström and Hofbauer found out that large parts of Rajani's argumentation was correct in the case of Namibia, and they could also add one additional factor: the cost of maintenance and operation. In their interviews, they found that the opinion at SchoolNet was that the maintenance and operational costs for commercial products such as for Microsoft Windows, was larger than they were for the open source products they had chosen (SUSE Linux). The operational security was higher because it was more stable, which also made it cheaper. This fact lowered the total TCO (total cost of ownership) for the ICT. Furthermore, Hafström and Hofbauer confirmed their thesis that if there were a possibility to have software, the preference was to have it in one's local language. At SchoolNet, many realized that they could easily translate and configure the software to the local language if they wanted. However, many also said that they did not find this necessary since English is Namibia's official language.

Another advantage other than language with free software is the possibility to develop new and better versions of an application or adjust to local customs and practices. The SchoolNet coworkers considered this a great advantage in comparison with non-free software. The Western world mostly develops non-free software for its western culture. For example, software used in American schools does not provide for the needs of pupils in Namibia. They gave an example: most Namibians do not eat bread or sandwiches in the way American or Western people do; many Namibians have never heard of the word 'sandwich'. Still they must learn English words such as 'peanut butter and jelly sandwich' because they use software created for American children [Hafström, Hofbauer, 2005-10-16].

Which were the biggest difficulties in the case of Namibia? According to Hafström and Hofbauer the main problem was the short supply of an educated workforce. Namibia suffers, as many other developing countries, of brain drain; the best-educated people leave the country to find work where the possibilities are better. Even if SchoolNet succeeded in installing and operating Linux, they said that when they encountered problems, they had a difficult time solving them. It was difficult to get local support.

One of the conditions Hafström and Hofbauer found to be critical for a successful IT-adaptation was physical access; that is, the region needed a well functioning IT infrastructure. "Physical access is a key factor for a successful implementation and it is therefore important to control that the existing infrastructure meets the demands." [Hafström, Hofbauer, 2005-10-16]. They support the Bridges opinion of the importance of a well-built ICT infrastructure. When comparing their conclusions against the twelve critical factors Bridges presented to fulfill real access, you could see agreement on most levels. Hafström and Hofbauer end their study by presenting 
the following eight important factors for a successful IT-adaptation in a developing country [Hafström, Hofbauer, 2005-10-16]:

- The technology must address real, experienced problems in the country.

- The technology must make sense for the people that are going to use it.

- The technology must provide sustainable solutions. The software cannot be outdated and demand upgrades every year.

- The essential physical infrastructure must be installed and the citizens must be able to afford it.

- It is important to realize the importance of local champions that use the technology and can act as models.

- The importance to focus on the right target group.

- The importance that technology is implemented to solve people's problems, not to increase them.

- The importance to focus and understand structures and attitudes in a society; people are likely to follow official institution's lead.

\section{Conclusions}

By way of introduction, one may ask some questions such as:

Can the introduction of free and open source software and the use of ICT in any way change the prerequisites of the developing countries?

In what ways can free software, open source, and ICT change the development of a country?

Is it the software that is the main need in focus for the developing world, or is it something else?

Are the opinions about free and open software and ICT the same in the industrialized and the developing world?

Depending on which country in the developing world you reference, they have different needs depending on the given basic conditions. A lesson learned is that discussions regarding the possibilities of free software and open source are a bit dashed when one realizes that at many places there is a need for ICT on a much lower level-a need for first filling the basic prerequisites. Of what use is free software if people cannot afford Internet access, or even worse, if there is no Internet access available or no computer or electrical power exists.

If one assumes the fulfillment of the basic conditions for ICT, one can notice several examples where free and open software can contribute to development. A school can have access to word processing editors free of cost instead of buying equivalent software for expensive licensing money (for example, Open-Office in contrast to Microsoft Office), you can adjust applications so they fit local customs and practices instead of something that is adjusted for an American or at least for a Western market. The most basic condition is the use of a free operating system instead of one that costs money, and by so, renders possible the use of computers

Another important aspect on advantages of free software is that they usually do not demand the newest or best hardware. Companies release new versions of software's continually that demands better and better hardware. Developing countries cannot count on a constant flow of used hardware to them, or for that 
matter, buy it themselves. System developers in Western countries do not as much have to take computer memory or CPU load into consideration when programming applications as developers using hardware from the eighties or nineties. The West regards hardware relatively inexpensive, a fact that is not applicable in the rest of the world. Developing countries need stable applications that work without constant upgrade, neither of the hardware nor the software.

It is difficult to say in general that the opinions regarding free and open software and ICT differentiates between the developing and industrial countries. If you compare individual developers the attitude positive for the most part, but it does not mean that you develop the same things. Programmers in the West do not have to develop applications as a support for education. These types of applications are already in place. Then of course, you could always choose to do so if desired. For many programmers and users in developing countries, the situation is very different, especially when no possibility exists to buy applications (as for instance Microsoft Office due to the licensing fees). You must use FOSS software if you do not want to generate illegal copies.

Still, the good will of individual programmers or project team members is not enough. For FOSS to succeed in the developing world, one must have support at government level, as has happened in for instance Brazil, Peru, and Malaysia. FOSS demands existing ICT infrastructure, an infrastructure in which individual governments must invest. Only then can one fully succeed.

\section{References}

[bridges.org1, 2005-10-16]. Free/open source software (FOSS) policy in Africa: A toolkit for policy-makers and practitioners, bridges.org and the Collaboration on International ICT Policy for East and Southern Africa (CIPESA) 10 August 2005, http://www.bridges.org/foss/FOSSPolicyToolkit_10Aug05.pdf. p. 8.

[bridges.org2, 2005-10-16], http://www.bridges.org/digitaldivide/realaccess.html.

[FSF, 2005-10-17], Free Software Foundation, http://www.fsf.org/licensing/essays/freesw.html.

[Gosh, 2005-10-18], Gosh, Rishab Aiyer, in The Politics of Open Source Adoption, The European Politics of F/OSS Adoption, edited by Joe Karaganis and Robert Latham. Social Science Research Council (SSRC), Version 1.0, May 2005, http://www.ssrc.org/programs/ccit/publications/POSA1.0.pdf, pp. 14-15.

[Hafström, Hofbauer, 2006-04-22], Hafström, Carolina and Hofbauer, Jessica. IT Adoption in Developing Countries, Department of Informatics, School of Economics and Commercial Law, University of Gothenburg, 2004, http://www.handels.gu.se/epc/archive/00003927/01/Nr\%5F39\%5FCH\%2CJH.pdf, pp.5064.

[Rajani, 2006-04-22], Rajani, Niranjan. Free as in Education - Significance of the Free/Libre and Open Source Software for Developing Countries, Ministry for Foreign Affairs, (Helsinki, Finland. 2002/2003), http://www.maailma.kaapeli.fi/FLOSS_for_dev.html, chapter 1, chapter 6 . 
[Raymond, 2006-04-22], Raymond, Erik. The Cathedral and the Bazaar, 2002. Version 3.0, 2002/08/02, http://www.catb.org/\%7Eesr/writings/cathedral-bazaar/cathedralbazaar/ar01s11.html.

[SchoolNet, 2005-10-16], SchoolNet Namibia, http://www.schoolnet.na/about/history.html. [Sourceforge, 2005-10-18], http://sourceforge.net/.

[SCB, 2005-10-17], Statistical Central Bureau SCB, http://www.scb.se/templates/tableOrChart__112387.asp.

[Ubuntu1, 2006-04-22], http://www.ubuntu.com/.

[Ubuntu2, 2006-04-22], http://www.ubuntulinux.org/.

[UNCTAD, 2005-10-17], United Nations Conference on Trade and Development. Ecommerce and development report 2004, Internet edition, prepared by the UNCTAD secretariat. United Nations, New York and Geneva, 2004, http://www.unctad.org/en/docs/ecdr2004_en.pdf, pp. 1-32.

1 For a discussion regarding the idea of non-free, please refer to http://www.gnu.org/philosophy/words-to-avoid.html\#Commercial. In this context non-free is used instead of the more common, but incorrect word, commercial (as in commercial software). A commercial software can be both free and non-free, therefore the careful distinction between the both.

2 The words FOSS and FLOSS are both used because the two researchers in their texts use the words respectively, FOSS is used by Rishab Aiyer Gosh, and FLOSS is used by Niranjan Rajani. Not for any other reason.

3 To read more about the Ubuntu Linux license rules, please refer to: http://www, ubuntu.com/ubuntu/licensing/document_view. 